\title{
28 Research Square \\ The Role of Agricultural Extension Programs On Crop Farming Technical Efficiency
}

\section{Nicolas Lampach}

KU Leuven: Katholieke Universiteit Leuven

\section{Phu Nguyen-Van}

Paris-Nanterre University: Universite Paris-Nanterre

Nguyen To-The ( $\nabla$ tothenguyen@gmail.com )

VNU UEB: VNU University of Economics and Business https://orcid.org/0000-0002-8839-255X

Tuan Nguyen-Anh

VNU UEB: VNU University of Economics and Business

\section{Research Article}

Keywords: Agricultural extension, Crop farming efficiency, Meta-analysis, Multiple Imputation, Publication bias, Inverse Probability of Treatment Weighting

Posted Date: October 22nd, 2021

DOI: https://doi.org/10.21203/rs.3.rs-891170/v1

License: (c) (i) This work is licensed under a Creative Commons Attribution 4.0 International License. Read Full License 


\section{Abstract}

Extension services have become the gold standard for agricultural development programs to spur farm productivity and enhance farmers' livelihood. Scholars from distinct strands of research have contested the virtues of these programs as systematic reviews failed to disentangle the different causal paths. We aim to unpack the relationship between these two constructs, and more specifically explore the main determinants causing systematic variabilities of the technical efficiency estimates from well-known published crop-farming studies. A meta-regression analysis is implemented by collating 335 observations from 199 farm-level studies to review the direct impact of agricultural extension activities on farming performance. While the implementation of expansion programs tends to be nonrandomly distributed in our sample, we employ the inverse probability of treatment weighting to correct for potential selection bias. The absence of a publication bias in found studies our meta-analysis is empirically identified. Our empirical findings are robust when multiple imputation method is employed to mitigate the missingness of observations. Consonant with the theory of agricultural extension, we find that extension significantly improves technical efficiency by $4.8 \%$ to $7.6 \%$. Farm productivity significantly differs in country level characteristics, type of crops and model specification.

JEL Classification: Q16, 018, C14, C29

\section{Introduction}

It is indisputable that agriculture is an inherent component of the economic development and human welfare. With a surge in food prices, depletion of natural resources along with adverse concequenses of climate change, the carrying capacity of farm productivity is under stress encompassing far-reaching implications for farmers' livelihoods. The fundament of output growth stems from the extension of land area, increasing cropping intensity through water irrigation and boosting yields. Given that the potential of land expansion and availability of water supply appear to be reaching its limit at a global view, a more efficient utilization of natural resources through innovative ways of farming continues to play a substantial role in the future (FAO, 2012).

Agricultural extension is an innovation from the 20th century designed to stimulate agricultural development and to create incentives for farmers to adopt a new modern technology through the reduction of information acquisition costs (Alexandratos, 1995, Anderson and Feder, 2004). Extension programs have been introduced worldwide with the objective to upgrade human capital by diffusing knowledge on production methods, optimal input use and management practices to farmers (Alene and Hassan, 2003; Dinar et al., 2007). From nearly a million of extension workers advising farmers globally on a daily basis, the largest share of agents is located in low and middle-income countries, most notably with $70 \%$ in Asia (Bahal, 2004). Although, a number of successes have been documented, critics posit deficiencies in the performance of extension systems as a result of low staff morale, financial stress, poor accessibility to agricultural advance techniques, misuse of extension programs due to political connectedness or the failure to remain farmers' interest in the long-term training (Agitew et al., 2018, Anderson and Feder, 2004, Jones and Kondylis, 2018, Rivera et al., 2002).

Whereas scholars develop various metrics to analyze the productivity growth in agriculture, we confine ourselves in this paper to the technical/farming efficiency defined as the ratio of observed output and maximum output with fixed inputs or, alternatively maximizing output with available inputs and technology ${ }^{[1]}$ (Farrell, 1957).

With the growth of literature on technical efficiency in the agricultural field, substantial efforts have been made to identify the main drivers explaining systematic disparities in the efficiency estimates (Bravo-Ureta et al., 2007, lliyasu et al., 2014, Jiang and Sharp, 2014, Thiam et al., 2001). Most notably, the study by Bravo-Ureta et al. (2007) applies a

Page $2 / 23$ 
metaregression analysis on the technical efficiency in farming and it reveals that the average efficiency estimate is higher for animal production in comparison with crop farming. Despite their careful investigation, the operationalization of the data is limited. We argue that a more fine grained review on farm performance by analyzing separately animal and crop production classification would not only expand our understandings on the technical feasibility within each system, but also allows to provide distinct policy implications for both groups.

Since the majority of extension policies entailed supply-driven activities with a primary focus on the productivity improvement of basic food crops (Swanson, 2006b), we restrict our analysis merely to crop farming studies. While cereal is the most prevalent crop with its cultivation exceeding $20 \%$ of global land surface ${ }^{[2]}$, minor crop groups likewise vegetables, fruits, root/tuber, nuts and other fibers take up less than $2 \%$. Under the future climate scenarios, the existence of low crop diversity in many regions of the world is alarming as it does not only accelerate shifts in pest occurrence and plant diseases-negatively affecting food production-, but also impeding rural livelihoods (Leff et al., 2004, Lin, 2011).

Displayed in Figure 1 is the number of scientific articles ${ }^{[3]}$ reporting the technical efficiency in the field of agriculture over the last decades. In addition to the steady rise of attention given by the scientific community on the concept of extension over time, we also observe that government expenditures in research and development is soaring at the same speed. Given this positive trend, systematic reviews and meta-analysis are crucial tools to design effective decision making. Meta-analysis also provides a common basis to clarify a specific research question and review puzzling findings from large number of cross sectional/longitudinal studies within a certain research field. It has become an increasing popular and widely applied method in a broad range of disciplines (Gurevitch et al., 2018). The main idea behind the methodology is to combine the results and findings from independent studies. Gathering the empirical estimates from available scientific resources - the reported mean of technical efficiency scores - a regression model is best employed for explaining the variation of the estimations based on the fundamental divergences across studies. Stanley et al. (2013) reports that no less than 200 meta studies are conducted per year on economic topics. ${ }^{[4]}$

Although, systematic reviews by Birkhaeuser et al. (1991), Evenson (1997) and Maredia et al. (2000) indicate some evidences that extension schemes play a significant effect on output, it is difficult to build empirically a direct causal relationship. The effectiveness of extension programs on farm productivity depends on how services are conveyed on specific circumstances of recipients. Anderson and Feder (2004) stress that measuring the effect of extension measures on farm performance is difficult due to measurement errors (i.e weak accountability) or the mutual influence of other systematic and random effects (e.g. price votality, credit hinderance, and climate). For this reason, a rigorous and careful examination of econometric and quasi-experimental methods represent a necessary condition to draw robust policy implications from the empirical results.

Findings of studies examining the effect of extension services on agricultural technical efficiency are disparate, hence our understanding about the effectiveness of extension programs appears to be fragile and fragmented. While Asres et al. (2014), Alene and Hassan (2003), Binam et al. (2004), Bravo-Ureta and Evenson (1994), Ofori-Bah and Asafu-Adjaye (2011) found no significance in the technical efficiency differences of both groups agricultural extension participants and non-participants, others manifested that there was a positive and significant connection between the contact with extension agents and farm performance (Cerda'n-Infantes et al., 2008; Dinar et al., 2007; Ho et al., 2014; Owens et al., 2003; NguyenVan and To-The, 2016; Villano et al., 2015; Wollni and Bru“mmer, 2012).

In view of the prevalence of non-experimental studies in the agricultural and development economics literature, we examine the direct impact of agricultural extension services on technical efficiency in accordance with other main 
determinants driving systematically differences in the efficiency estimates in crop farming studies. Hence, our contribution is to provide robust evidence on the effect of agricultural extension on farm productivity in crop framing. In light of the increased interest in agricultural extension programs in most parts of the world, knowing whether extension policy is an effective strategy to improve farm productivity can lay out an vital insight to both policymakers willing to invest in agricultural extension and private research firms delivering extension services.

A sample of 335 observations of 199 farm level studies on crop plant is collated to estimate the technical efficiency by the means of meta-regression analysis. The majority of the studies report only the mean and the range of technical efficiency, however the variance (or standard deviation) is needed for the meta-analysis. Following Hozo et al. (2005), we estimate the variance using the mean, the low and high range, and the sample size. Additional complication arises from missing sample variance for studies reporting solely the mean technical efficiency. To deal with missing observations in our meta-analysis, we draw on multiple imputation method to replace missing observations with imputed values (Chowdhry et al., 2016). While the inclusion of extension programs in domestic policies is not randomly distributed across our sample, we control for selection bias using the inverse probability of treatment weighting technique.

Graphical and numerical assessment tools suggest the absence of a publication bias for both complete case and imputed data. Our study contributes to the applied agricultural economics literature by empirically validating the technical efficiency in crop farming studies and the development literature by reviewing the effect of extension policies on farm performance. Consonant with the agricultural extension theory, studies focusing on extension have found higher level of farm productivity than those who do not.

The remainer of this paper is structured as follows. Section 2 introduces the concept of metaanalysis followed by Section 3 presenting the meta-regression and our strategies to deal with missing data and sample selection problems. Section 4 explores potential publication bias in studies used in our meta analysis. Section 5 presents the estimation results and discusses our findings. Section 6 gives conclusion of the study and provides policy implications within the agricultural extension literature.

[1] Different definitions of productivity are possible, ranging from simple notion of yield per acre to more complex measure of total factor productivity and technical frontier. For the discussion on the concept and measurement of agricultural productivity, see Christensen (1975), Kopp (1981) and Porcelli (2009).

[2] i.e $61 \%$ of the total cultivated area.

[3] Google Scholar free services is of great help to discover quickly scientific resources. One main drawback is that Google Scholar is lacking information on the actual size and coverage of the scientific collections (Jacs'0, 2005, Mayr and Walter, 2007). The retrieved hits should not be taken as a measure of scholarly production or impact, but rather as a macroscopic view of the content indexed by Google Scholar.

[4] Interested reader may find further information on meta-analysis in the field of economics inBravo-Ureta et al. (2007); Card and Krueger (1995); Dalhuisen et al. (2003); Espey et al. (1997); Jiang and Sharp (2015); Moreira and Bravo-Ureta (2010); Thiam et al. (2001) and among others.

\section{Materials}

\subsection{Meta data}

The application of meta-analysis framework needs important consideration by following a clear and rigorous procedure to review the literature. ${ }^{[1]}$ Original studies were identified through keyword searches (e.g., "Technical Efficiency”, “Technical Progress”, “Crop”, “Crop Farming”, “Extension Policy”, “Extension Services”, “Agricultural 
Extension Measures" "Meta Analysis"). Published and non-published studies were searched in English between January 1991 and August 2019 through ISI Web of Knowledge, Google Scholar, Scopus, and AgEcon

Search. Regarding present paper, a comprehensive review was conducted in the following peer-reviewed journals: American J. of Ag. Econ.; World development; Australian J. of Ag. Econ.; Canadian J. of Ag. Econ.; European J. of Operational Research; Eur Rev. Ag. Econ.; J. of Ag. and Applied Econ; J. of Ag. Econ.; Ecological Econ.; J. of Prod. Analysis., Food Policy and other journals. ${ }^{[2]}$

Given that the eligible studies report several technical efficiency coefficients for similar or different crop plant types, the data under analysis include a total of 335 data entries. ${ }^{[3]}$ Aggregated and temporal pattern on the variation of technical efficiency between income groups and type of crops are provided in Supplementary Materials (see Figure 9-14).

Since each study may contain multiple observations, the data has a nested hierarchical structure. The key future of nested data is that observations within a study are more similar than the one from other studies (Galbraith et al., 2010). Our data collection differs from Thiam et al. (2001) and Bravo-Ureta et al. (2007) who considered the average technical efficiency as a summary measure referring to the whole sample for any particular study. Visually inspecting the regional spread of the eligible studies in Figure 2 reveals that a high number of studies targeting at extension service programs is concentrated in Eastern Africa, Southern and Southeastern Asia and less so in South America, Central America, Middle Africa, Northern America and Europe. This pattern is consonant with the so-called 'information commodification' trend of agricultural knowledge reflecting a change towards the value placed on technology transfer systems (Buttel, 1991). Unlike low-income countries suffering from under-investments in extension, low-middle and especially middle-income countries have begun to invest in extension services as one strategy to reduce poverty by generating incomes through training and information sharing (Rivera, 2001). This also supports the argument that the implementation of agricultural extension programs target on individual group of farmers in specific spatial areas and thus introducing a selection bias.

\subsection{Relationship between agricultural extension and technical efficiency}

Scholars have discussed a large set of factors, ranging from econometric techniques, choice of functional form, type of data, mathematical programming techniques to number of observations potentially affecting the estimated technical efficiency (Bravo-Ureta et al., 2007; Thiam et al., 2001). Nevertheless, a key determinant largely neglected by previous meta-analysis research is the effect of extension measures on technical efficiency. Governments may support farmers by offering extension services encompassing a wide array of communication and learning activities organized by educators for farmers. Extension agents offer training to farmers on harvesting and conservation techniques, application of new technologies, fertilizers and pesticides, technical instruction of plant production or agricultural marketing. Associated with a strong social dimension, the workload of extension schemes has urged to become more diversified through the provision of socio-demographic guidance to maintain not only farmers income levels, but also to safeguard rural livelihoods (Swanson, 2006a). Agricultural extension operates within a broader knowledge system integrating research, agricultural training, and tailors down to harness agricultural-related technology, knowledge and information to improve farm productivity (Rivera, 2001).

Evaluating extension activities on farm performance is perceived through the lens of two distinct concepts in the production analysis theory. While its direct effect on the output is assessed through the inclusion of a separate input factor in the production function, it can also serve as a determinant in the inefficiency function to explain divergences 
in technical efficiency among farmers (Dinar et al., 2007; Gebrehiwot, 2017). In this way, the effect of extension services is assessed indirectly through the potential output gain.

Although, the relatively low number of studies in our sample using extension measure as input factor in the production function does not allow to differentiate between these two concepts in our meta-regression analysis, we presume the above mentioned condition to review the causal relationship between the direct effect of extension activities on farm performance (see Figure 3).

From a methodology perspective, each approach is informative by itself, but constitutes limitations as the effect of extension services is measured directly and indirectly on the performance of the farm. One could argue that these approaches are equivalent under some conditions. In the Cobb-Douglas production function, for instance, $Y=A K a L \beta E Y$ where $\mathrm{E}$ denotes extension services representing an additional input besides capital $\mathrm{K}$ and labor $\mathrm{L}$ and supposing that the new productivity term is $B=A E Y$ leads to the production function $Y=B K a L \beta$ where productivity (or technical efficiency) term B covers the variable extension.

The meta-analysis creates a portal connecting information on the technical efficiency to a large set of characteristics from all relevant studies. Our primary aim is to determine the impact of extension services on the technical efficiency estimates when controlling for different crop plant types, model specifications, methodologies and study-specific characteristics. With this is mind, our hypothesis to be investigated in this study can be summarized as following:

- Hypothesis: Extension has a positive effect on the technical efficiency in crop farming studies

[1] Note that Meta Analysis of Economics Research (MAER) network provides helpful guidelines and recommendations on how meta-analyses in the field of economics should comply with reporting protocols requirements (Stanley et al., 2013).

[2] Grey literature relates to the realm of agriculture, economics, agricultural economics, productivity analysis or general review articles.

[3] An overview on relevant information of the eligible studies is provided in Supplementary Materials. Moreover, we develop an interactive web app to navigate the data information, see https://eussue.shinyapps. io/meta_analysis/.

\section{Methods}

Lacking information on the variance and the range of the estimated technical efficiency in our sample impedes the meta-regression analysis. A first solution to this problem is to estimate the variance of farm performance for those studies reporting the mean, range, and sample size (Hozo et al., 2005). However, the amount of missing observations in our data set still accounts for $6.3 \%$ after the variance estimation which might potentially lead to inaccurate estimates. Deleting missing cases would only be preferable if these are missing completely at random (Rubin, 1976). A frequently used strategy to mitigate the impact of missingness and the bias of estimates in meta-regression analysis is multiple imputation method (Burgess et al., 2013; Higgins et al., 2008). Under the key assumption that observations are not missing completely at random, the imputation model replaces missing observations with imputed values (Rubin, 1976). To verify the underlying assumption of the imputation application, we perform Little (1988) test. The latter is counter the hypothesis that observations are missing completely at random $\left(p_{\text {value }}<0.001\right)$. Thus, we can perform within-study imputation using predictive mean matching. It has been shown that predictive mean matching preserves effectively the original distribution of the empirical data (Kleinke, 2017). This approach imputes actual observed values from a pool of $k>0$ values (i.e donor pool) with the most closest distance to the predicted value for the missing case. ${ }^{[1]}$ 
Running a total number of $m=100$ imputed data set, we analyze each set separately and combine subsequently the multiple imputed estimates according to Rubin's rule. Plotted in Figure 4 is the original and imputed distribution of the covariates including missing cases. It can be seen that the imputed distributions (i.e dashed line) largely overlap with the original distribution (i.e solid line) establishing a sufficient degree of confidence in the effectiveness of the multiple imputation method.

To verify our hypothesis, we estimate a weighted least square meta-regression with estimated weight is estimated by the inverse standard error of the technical efficiency estimates for both complete case analysis and imputed data sets. Alternatively, we run a model with weights equal to the inverse range of technical efficiency estimates. Weighted regression method corrects for heteroscedasticity by assigning adjusted weights for each relevant study, smaller weights to studies are given large standard errors in technical efficiency estimates and vice versa. To explain the heterogeneity among the reported estimates, we control for withinstudy specific characteristics, regional disparities, data characteristics, model specification differences, and study fixed effects.

The specification for the model is:

$$
T E_{i}=\alpha_{1}+\beta_{1} E X T_{i}+\sum_{k=1}^{K} \gamma_{k} Z_{i t k}+\tau_{i} t+\epsilon_{i}
$$

where the dependent variable TE is the technical efficiency as reported in the crop farming studies. Estimating Eq.1 with weights equal to the inverse standard errors of technical efficiency estimates $\operatorname{SE}\left(T E_{i}\right)$, we assume that the error term $i$ is independently distributed with mean zero and variance $1 / S E\left(T E_{i}\right)^{2}$. Alternatively, we apply weights corresponding to the inverse range of technical efficiency estimates $R\left(T E_{i}\right)$ implying that $i$ is independently distributed with mean zero and variance $1 / \mathrm{SE}\left(\mathrm{TE}_{\mathrm{i}}\right)^{2}$. While the intercept a1 measures the mean effect size of the technical efficiency, our variable of interest is EXT denoting the inclusion of extension policy expressed as a dummy variable whether the study employs agricultural extension measures. $Z_{i k}$ entails the control variables and tit is study fixed effects to rule out unobserved heterogeneity. $Z_{\mathrm{ik}}$ comprises the economic development from various income groups under study (LIE, LMIE, MIE, UMIE, HI), type of crop plants (Crops1, Crops2, Crops3, Crops4, Crops5, Crops6, Crops7, Crops8, Crops9), cross-sectional data (Type), number of observations (Obs), model specification based on Data Envelopment Analysis (DEA) and specification of the production function (Other, $C D, T L$ ).

Based on World Bank (2016) country classification by income level, we employ dichotomous variables to capture the national economic development under study. We use a set of five dummy variables, low income economy (LIE), lowmiddle-income ( $L M I E)$, middle-income (MIE), upper middle-income (UMIE) and high-income (HIE). The distribution of the regional origin is illustrated in Supplementary Materials (Figure 7). With the largest proportion of studies in our sample coming from $L M I E$, we choose this category as the reference in the meta-regression.

According to FAO (2012), we use the crop classification to partition systematically the plant production types of the relevant crop farming studies. Nine dummy variables-cereals (Crops1), vegetables and melons (Crops2), fruit and nuts (Crops3), oil seed (Crops4), root and tuber (Crops5), beverage and species (Crops6), leguminous (Crops7), sugar (Crops8) and non-food (Crops9) - are employed with cereals representing the largest majority in our sample. The share of crop types in our sample is displayed in Supplementary Materials (Figure 8). We merge three categories (Crops3, Crops7 and Crops8) owing to low number of frequencies and we create a new dummy category denoted as Miscellaneous.

The specification of the production function is measured by three dummy variables where $T L$ denotes the trans-log, $C D$ represents the Cobb-Douglas function $(C D)$ and Other stands for other functional forms (served as the reference 
category).

Even though agricultural extension programs have been implemented intensively in lowmiddle-income countries in the last years, crop types and extension services are interconnected and there is no standardization of extension that can be used uniformly by different crop types. The substantial disparities in the technical efficiency among distinct crop types can be attributed to dissimilarities on the choice of extension activities. Extension service and the underlying crop are mutually inclusive and hence the dissemination of certain modern technologies target only on a determined crop type. To account for potential selection bias, we apply inverse probability of treatment weighting (IPTW) technique to compare studies that include extension as a determinant into the technical inefficiency model to those which do not.

IPTW relies on the computation of propensity scores - predicted likelihood of conditional treatment assignment on observed characteristics - defined as $\psi=P(E X T=1 \mid X)$ and typically estimated via logistic regression. We presume that the likelihood of the implementation of extension program is conditional on the economic development of the region under study and the type of crops. Whereas propensity score matching formulates matched sets of treated and nontreated units sharing similar propensity scores, IPTW assigns greater weights to units in the control group which resembles those in the treatment group (Austin and Stuart, 2015, Becker and Ichino, 2002). In case of a binary variable, the inverse probability of treatment weight can be expressed as: $w=\frac{1}{\psi} E X T+\frac{1}{(1-\psi)}(1-E X T)$ where EXT denotes the inclusion of extension measures (treatment) in the study and $\psi$ the propensity score of treatment assignment. The main intuition of this approach is to make treatment (inclusion of extension services) and control groups (no-services) more similar by using the full data set without restricting it only to the matched samples. Prior to presenting our metaregression results, we verify graphically and numerically whether a publication bias is apparent in the crop farming studies used in the meta-analysis.

[1] An illustration and detailed explanation about the implementation of predictive mean matching in agricultural research can be found in Lampach et al. (2019).

\section{Publication Bias}

There is a large degree of consent that the presence of biases in systematic reviews might influence the precision and accuracy of the treatment effects. The fact that studies reporting relatively larger effect sizes have better tendancy to be published in academic journals than those withx smaller effects and therefore have higher odds to end up in metaanalysis is widely known as publication bias. Identifying the existence of the publication bias is crucial to draw accurate conclusions from systematic reviews (Hang et al., 2017, Sutton et al., 2000). Funnel plots are helpful graphical tools to spot unbiased samples. A symmetric-inverted funnel plot indicates that the deviations of the mean technical efficiency decline with increasing precision in their estimates (Lin and Chu, 2018). Figure 5 displays the relationship between study size and technical efficiency estimates to detect publication bias in the studies included in the meta analysis.

We use the standard error on the vertical axis and the mean technical efficiency estimate on the horizontal axis. Detecting asymmetries hints to a publication bias. The precision in the estimation of the technical efficiency is more accurate as the size of the relevant crop farming studies increases. The results from small sample studies will therefore scatter more widely while larger spread narrower around the overall effect (i.e solid line).

Panel $5 \mathrm{a}$ and $5 \mathrm{~b}$ point to the absence of publication bias. This result can be confirmed by regression tests for funnel plot asymmetries in meta-analysis. The Egger test performs a linear regression of the technical efficiency estimates on their standard errors. We cannot reject the null hypothesis that small studies have an effect in the meta-analysis

Page $8 / 23$ 
( $p$ value $=0.155$ and pvalue $=0.178$, respectively for both complete case and multiple imputation). We can be confident that there is no evidence for the occurrence of publication bias in the reported estimates.

\section{Estimation Results}

Table 1 presents the baseline estimation results of the weighted least square meta-regression model. We report clustered standard errors at the level of studies (Espey et al., 1997, Thiam et al., 2001). Column (la and IIc) and (Ib and IId) present the estimates for the complete case analysis and imputed data set, respectively. Most of the parameters of Model I and II are significant at $5 \%$ level. Weighted $R^{2}$ along with AIC and BIC point to model with complete case analysis (I(a) and II(c)) as the best fit to the data.

Our empirical results manifest studies using extension measures achieve significantly higher levels of efficiency in crop farming than those who do not. This result holds across all model specification and confirms our hypothesis. Consonant with agricultural extension theory, our empirical results demonstrate a positive relationship between farm extension activities and technical efficiency with an effect size varying between $4.8 \%$ and $7.6 \%$. This finding lends support for the argument that farmers could increase agricultural output from the contact of extension agents through a better utilization of available resources given the recent condition of technology. Gains in output deduced from improvement in productivity are crucial to food security in many countries where resources are scanty and the opportunity of technology adoption is meager. Moreover, extension services do not only accelerate the information dissemination process, but also enhance farmers' managerial ability resulting in higher productivity (Asres et al., 2014; Birkhaeuser et al., 1991; Evenson, 1997; Feder et al., 1999; Umali-Deininger, 1997). The effectiveness of extension work may depend on farmer's access to information, education, larger farm holdings and better access to markets. Since information-intensive technologies require an increase demand in information diffusion systems, illiterate farmers located in regions with inadequate physical infrastructures face difficulties in adopting new agricultural technologies (Anderson and Feder, 2004; Asres et al., 2014).

Reported in Table 2 are the results from our meta-regression analysis applying IPTW technique for complete case analysis. Agricultural extension services, though, remains positive and highly significant when controlling for potential endogeneity arising from sample selection bias. The same result holds, when we set different model specifications to estimate the propensity scores (see Table 3 in the Supplementary Materials). Variations in the implementation of extension programs, therefore, has the power to explain disparities in farm productivity. Even though the best model fit in Table 3 appears to be Model (3), Figure 6 suggests that the largest overlap between treatment and control group is given by Model (2) when specifically controlling for income groups in the logistic regression.

Significant and positive effect is found for different crop types. While most of the estimates are negative and not significant, studies for vegetables and melons (Crops3) produce higher estimates than those for cereals production across all model specifications. We argue that this result appears reasonable owing to their higher value per acre (Fernandez-Cornejo, 1994). Another reason might be that vegetable production in controlled-environment - a technology-approach applied in many upper-middle and high-income countries- enables farmers to manage the growing environment for improved yield and quality. In contrast to controlled-environment agriculture, crop production in open field is adversely affected by water shortage and extreme weather events (Salisbury and Bugbee, 1988). With respect to the low degree of diversification and the poor technical efficiency of other crops, this can have substantial consequences on farmers' livelihood. Evidence has shown a strong association between degree of diversification and productivity in crop farming (Ogundari, 2013; Manjunatha et al., 2013; Mkhabela, 2005). The efficiency in the use of resources might lead to reduced system diversity and thus endanger resilience. Higher degree of crop diversification would enhance the resilience, albeit farmers would end up with lower levels of productivity due to poor technical 
efficiency of other crops. This trade-off between efficiency in the resource use and land-use diversity might indirectly influence farmers' cropping decision and consequently farm performance.

Contrary to the findings of Thiam et al. (2001) and Bravo-Ureta et al. (2007), our empirical results reveal that studies in high-income countries achieve higher technical efficiency estimates than the group of low-middle. Divergences are likely to be attributed to different operationalization of the regional origin variable and the sample size employed in the meta-regression analysis. Our finding is congruent with the common trend in investments of agricultural R\&D and extension. While the spending gap between rich and poor countries widened steadily from 1980 until 2011, low-income countries failed to align with growth of other parts in the globe, such that their share of global public expenses diminishes dramatically over the past half century in agricultural research and extension services (Pardey et al., 2018). The association of dysfunctional agricultural extension systems and low levels of technical efficiencies in low-income countries has been extensively reported by the developing and agricultural economics literature (Anderson and Feder, 2004, Birkhaeuser et al., 1991, Rivera, 2001, Rivera et al., 2002, Swanson, 2006b).

The coefficient of cross-sectional studies (Type) is negative and statistically significant in Table 3 indicating that crosssectional studies produce lower estimates than longitudinal studies. The coefficient of DEA is positive and significant in Table 1 and 2 suggesting that studies employing deterministic models achieve higher technical efficiency estimates than stochastic ones. Both findings are similar to those reported by Thiam et al. (2001) and Bravo-Ureta et al. (2007).

The effect of the functional form on farm performance displays mixed results across all employed models (the reference category for this group is other). While the trans-log estimation is positive and significant in all model specifications in Table 1 and 3 and the Cobb-Douglas is not, our findings diverges from Ahmad and Bravo-Ureta (1996), Bravo-Ureta et al. (2007), Resti (2000) and Thiam et al. (2001) who found that studies using Cobb-Douglas function yield higher technical efficiency estimates compared to those applying other functional forms. Consistent with Thiam et al. (2001), we find a positive and non-significant effect for the number of observations (i.e expressed in log).

\section{Summary And Conclusion}

The empirically literature on the effect of extension activities on farm productivity, agricultural growth and technical efficiency is fragmented and suffers from methodological flaws in identifying the direct causal relationship. We apply a meta-regression analysis by using a sample of 335 observations from 199 farm level studies to untangle the relationship between these two constructs. The numerical and graphical assessment reveal no presence of publication bias of the eligible studies included in the meta-analysis. Applying the inverse probability of treatment weighting to rule out selection bias, our findings lend support for our hypothesis that extension programs have a significant and positive impact on crop farming efficiency. Hence, extension helps to reduce the technical inefficiency gap. Another important result points out significant differences among crop types suggesting that studies for vegetables and melons yield higher level of productivity compared to cereals. Our findings are robust when accounting for missing observations in our data set by the means of multiple imputation method. While the methodology proposed in this paper can serve as a basis to review the effect of agricultural extension services on the technical efficiency, it is also flexible enough to be applied to distinct agricultural output measures and production systems.

These results have implications not only for evaluating farm productivity in crop farming, but also for designing effective agricultural extension programs to increase the efficiency in the use of available resources. Agricultural policies can rely on extension services to improve farm productivity by conveying information from local research to farmers. Our findings indicate that extension facilitate a shift to more efficient production methods and reduces management gaps. Highest marginal returns of public investments in agricultural extension services are most likely to be generated for production systems with low level of technical efficiency in early stages. While the highest level of 
productivity was obtained by vegetable production, it does though represent a very tiny proportion of the world's cultivated surface. However, there is a trade-off between the efficiency in the resource use and the degree of crop diversification. Although cereals production yield second best efficiency estimates in our meta-regression analysis, the large use of land for cereal production accelerates loss of agricultural biodiversity and reduced land cover diversity which makes farmers more vulnerable to climate change, natural hazards, pests and diseases. Nevertheless, a higher degree of crop diversification enhance the resilience but might also drive to a higher level of technical inefficiency. Investing in extension services may help to overcome this trade-off by training farmer's managerial ability to increase the technical efficiency in cultivating distinct crops. Policies aiming to enhance resilience by intensifying crop diversity may use extension services to foster the productivity of other crops.

The effectiveness of agricultural extension services can be limited by institutional factors and constraints at the supply side over which extension management has simply no leverage. Regions with lower literacy rates, limited education, poor physical infrastructure and unfavorable market conditions cope with greater difficulties in benefiting of extension services and in adopting new technologies. Further research is needed to design and provide extension services to farmers in these less favorable environments around the world.

\section{Declarations}

Ethics approval and consent to participate: This article does not contain any studies with human or animal subjects.

Consent for publication: Not applicable.

Availability of data and materials: The datasets used and/or analysed during the current study are available from the corresponding author on reasonable request.

Competing interests: The authors declare that they have no competing interests.

Funding: No funding was received for conducting this study

\section{Authors' contributions:}

- Conceptualization: Nguyen-Van Phu, Nicolas Lampach, Nguyen-Anh Tuan and Nguyen To-The.

- Data curation: Nguyen To-The, Tuan Nguyen-Anh,

- Methodology: Nguyen-Van Phu, Nicolas Lampach.

- Supervision: Nguyen To-The.

- Writing-original draft: Nicolas Lampach.

- Writing-review \& editing: Nguyen-Van Phu and Nguyen To-The.

\section{References}

1. Agitew, G., S. Yehuala, A. Demissie, and A. Dagnew (2018): "Technological gaps of agricultural extension: Mismatch between demand and supply in North Gondar Zone, Ethiopia," Journal of Agricultural Extension and Rural Development, 10, 144-149.

2. Ahmad, M. and B. E. Bravo-Ureta (1996): "Technical efficiency measures for dairy farms using panel data: A comparison of alternative model specifications," Journal of Productivity Analysis, 7, 399-415.

3. Alene, A. D. and R. M. Hassan (2003): "Measuring the impact of Ethiopia's new extension program on the productive efficiency of farmers," in Proceedings of the 25th International Conference of Agricultural Economists 
(IAAE), vol. 16, 22.

4. Alexandratos, N. (1995): World agriculture: Towards 2010: FAO study, Food and Agriculture Organisation of the United Nations, Rome, Italy.

5. Anderson, J. R. and G. Feder (2004): "Agricultural extension: Good intentions and hard realities," The World Bank Research Observer, 19, 41-60.

6. Asres, E., I. Akira, Y. Kumi, and A. Arega (2014): "The effect of agricultural extension service on the technical efficiency of Teff (Eragrostistef) producers in Ethiopia," American Journal of Applied Sciences, 11, 223-239.

7. Austin, P. C. and E. A. Stuart (2015): "Moving towards best practice when using inverse probability of treatment weighting (IPTW) using the propensity score to estimate causal treatment effects in observational studies," Statistics in Medicine, 34, 3661-3679.

8. Bahal, R. (2004): Agricultural Research and Extension Systems: Worldwide Study of Human and Financial Resources, Concept Publishing Company.

9. Becker, S. O. and A. Ichino (2002): "Estimation of average treatment effects based on propensity scores," The Stata Journal, 2, 358-377.

10. Binam, J. N., J. Tonye, G. Nyambi, M. Akoa, et al. (2004): “Factors affecting the technical efficiency among smallholder farmers in the slash and burn agriculture zone of Cameroon," Food Policy, 29, 531-545.

11. Birkhaeuser, D., R. E. Evenson, and G. Feder (1991): "The economic impact of agricultural extension: A review," Economic Development and Cultural Change, 39, 607- 650.

12. Bravo-Ureta, B. E. and R. E. Evenson (1994): "Efficiency in agricultural production: The case of peasant farmers in eastern Paraguay," Agricultural Economics, 10, 27-37.

13. Bravo-Ureta, B. E., D. Sol'ıs, V. H. M. Lopez, J. F. Maripani, A. Thiam, and'

14. T. Rivas (2007): "Technical efficiency in farming: A meta-regression analysis," Journal of Productivity Analysis, 27, 57-72.

15. Burgess, S., I. R. White, M. Resche-Rigon, and A. M. Wood (2013): "Combining multiple imputation and metaanalysis with individual participant data," Statistics in Medicine, 32, 4499-4514.

16. Buttel, F. (1991): "The restructuring of the American public agricultural research and technology transfer system: Implications for agricultural extension," Agricultural Extension: Worldwide Institutional Evolution and Forces for Change. Elsevier Science Publishers. Amsterdam.

17. Card, D. and A. B. Krueger (1995): "Time-series minimum-wage studies: A metaanalysis," American Economic Review, 85, 238-243.

18. Cerdan-Infantes, P., A. Maffioli, and D. Ubfal' (2008): "The impact of agricultural extension services: The case of grape production in Argentina," Inter-American Development Bank Washington.

19. Chowdhry, A. K., R. H. Dworkin, and M. P. McDermott (2016): “Meta-analysis with missing study-level sample variance data," Statistics in Medicine, 35, 3021-3032.

20. Christensen, L. R. (1975): "Concepts and measurement of agricultural productivity," American Journal of Agricultural Economics, 57, 910-915.

21. Dalhuisen, J. M., R. J. G. M. Florax, H. L. F. De Groot, and P. Nijkamp

22. (2003): "Price and income elasticities of residential water demand: A meta-analysis," Land Economics, 79, 292308.

23. Dinar, A., G. Karagiannis, and V. Tzouvelekas (2007): “Evaluating the impact of agricultural extension on farms' performance in Crete: A nonneutral stochastic frontier approach," Agricultural Economics, 36, 135-146. 
24. Espey, M., J. Espey, and W. D. Shaw (1997): "Price elasticity of residential demand for water: A meta-analysis," Water Resources Research, 33, 1369-1374.

25. Evenson, R. (1997): "The economic contributions of agricultural extension to agricultural and rural development. Improving agricultural extension: a reference manual." Tech. rep., Food and Agriculture Organisation of the United Nations, Rome, Italy.

26. FAO (2012): Statistical Yearbook 2011: World Food and Agriculture, Food and Agriculture Organziation of the United Nations, Rome, Italy.

27. Farrell, M. J. (1957): "The measurement of productive efficiency," Journal of the Royal Statistical Society, 120, 253-290.

28. Feder, G., A. Willett, and W. Zijp (1999): Agricultural extension: Generic challenges and some ingredients for solutions, The World Bank.

29. Fernandez-Cornejo, J. (1994): "Nonradial technical efficiency and chemical input use in agriculture," Agricultural and Resource Economics Review, 23, 11-21.

30. Galbraith, S., J. A. Daniel, and B. Vissel (2010): "A study of clustered data and approaches to its analysis," Journal of Neuroscience, 30, 10601-10608.

31. Gebrehiwot, K. G. (2017): "The impact of agricultural extension on farmers' technical efficiencies in Ethiopia: A stochastic production frontier approach," South African Journal of Economic and Management Sciences, 20, 1-8.

32. Gurevitch, J., J. Koricheva, S. Nakagawa, and G. Stewart (2018): "Metaanalysis and the science of research synthesis," Nature, 555, 175.

33. Hang, M., J. Geyer-Klingeberg, A. W. Rathgeber, and S. Stockl“ (2017): "Measurement matters: A meta-study of the determinants of corporate capital structure," The Quarterly Review of Economics and Finance.

34. Higgins, J. P., I. R. White, and A. M. Wood (2008): "Imputation methods for missing outcome data in meta-analysis of clinical trials," Clinical Trials, 5, 225-239.

35. Ho, T. Q., J. F. Yanagida, and P. Illukpitiya (2014): "Factors affecting technical efficiency of smallholder coffee farming in the Krong Ana Watershed, Vietnam," Asian Journal of Agricultural Extension, Economics and Sociology, 3, 37-49.

36. Hozo, S. P., B. Djulbegovic, and I. Hozo (2005): "Estimating the mean and variance from the median, range, and the size of a sample," BMC Medical Research Methodology, 5, 13.

37. Iliyasu, A., Z. A. Mohamed, M. M. Ismail, and A. M. Abdullah (2014): "A meta-analysis of technical efficiency in aquaculture," Journal of Applied Aquaculture, 26, 329-339.

38. Jacso, P.' (2005): “Google Scholar: The pros and the cons,” Online Information Review, 29, 208-214.

39. Jiang, N. and B. Sharp (2014): "Cost efficiency of dairy farming in New Zealand: A stochastic frontier analysis," Agricultural and Resource Economics Review, 43.

40. --- (2015): "Technical efficiency and technological gap of New Zealand dairy farms: A stochastic meta-frontier model," Journal of Productivity Analysis, 44, 39-49.

41. Jones, M. and F. Kondylis (2018): “Does feedback matter? Evidence from agricultural services,” Journal of Development Economics, 131, 28-41.

42. Kleinke, K. (2017): "Multiple imputation under violated distributional assumptions: A systematic evaluation of the assumed robustness of predictive mean matching," Journal of Educational and Behavioral Statistics, 42, 371404.

43. Kopp, R. J. (1981): “The measurement of productive efficiency: A reconsideration," The Quarterly Journal of Economics, 96, 477-503.

Page $13 / 23$ 
44. Lampach, N., P. Nguyen-Van, and N. To-The (2019): "Robustness analysis of organic technology adoption: evidence from Northern Vietnamese tea production," European Review of Agricultural Economics, jbz018.

45. Leff, B., N. Ramankutty, and J. A. Foley (2004): “Geographic distribution of major crops across the world," Global Biogeochemical Cycles, 18.

46. Lin, B. B. (2011): "Resilience in agriculture through crop diversification: Adaptive management for environmental change," BioScience, 61, 183-193.

47. Lin, L. and H. Chu (2018): “Quantifying publication bias in meta analysis,” Biometrics, 74, 785-794.

48. Little, R. J. (1988): "A test of missing completely at random for multivariate data with missing values," Journal of the American statistical Association, 83, 1198-1202.

49. Manjunatha, A., A. R. Anik, S. Speelman, and E. Nuppenau (2013): "Impact of land fragmentation, farm size, land ownership and crop diversity on profit and efficiency of irrigated farms in India," Land Use Policy, 31, 397-405.

50. Maredia, M., D. Byerlee, and J. R. Anderson (2000): “Ex post evaluation of economic impacts of agricultural research programs: A tour of good practice," Available at: https://cgspace.cgiar.org/handle/10947/503 assessed on $15 / 10 / 2019$.

51. Mayr, P. and A.-K. Walter (2007): "An exploratory study of Google Scholar," Online Information Review, 31, 814830.

52. Mkhabela, T. (2005): "Technical efficiency in a vegetable based mixed-cropping sector in Tugela Ferry, Msinga District, KwaZulu-Natal," Agrekon, 44, 187-204.

53. Moreira, V. H. and B. E. Bravo-Ureta (2010): "Technical efficiency and metatechnology ratios for dairy farms in three southern cone countries: A stochastic meta-frontier model," Journal of Productivity Analysis, 33, 33-45.

54. Nguyen-Van, P. and N. To-The (2016): "Technical efficiency and agricultural policy: Evidence from the tea production in Vietnam," Review of Agricultural, Food and Environmental Studies, 97, 173-184.

55. Ofori-Bah, A. and J. Asafu-Adjaye (2011): "Scope economies and technical efficiency of cocoa agroforesty systems in Ghana," Ecological Economics, 70, 1508-1518.

56. Ogundari, K. (2013): "Crop diversification and technical efficiency in food crop production: A study of peasant farmers in Nigeria," International Journal of Social Economics, 40, 267-287.

57. Owens, T., J. Hoddinott, and B. Kinsey (2003): "The impact of agricultural extension on farm production in resettlement areas of Zimbabwe," Economic Development and Cultural Change, 51, 337-357.

58. Pardey, P. G., J. M. Alston, C. Chan-Kang, T. M. Hurley, R. S. Andrade, S. P. Dehmer, K. Lee, and X. Rao (2018): "The shifting structure of agricultural R\&D: Worldwide investment patterns and payoffs," in From agriscience to agribusiness, Springer, 13-39.

59. Porcelli, F. (2009): “Measurement of Technical Efficiency. A brief survey on parametric and non-parametric techniques," University of Warwick, 11, 1-27.

60. Resti, A. (2000): "Efficiency measurement for multi-product industries: A comparison of classic and recent techniques based on simulated data," European Journal of Operational Research, 121, 559-578.

61. Rivera, W. (2001): "Whither agricultural extension worldwide? Reforms and prospects," in Knowledge Generation and Technical Change, Springer, 291-311.

62. Rivera, W., M. K. Qamar, L. Van Crowder, et al. (2002): "Agricultural and rural extension worldwide: options for institutional reform in the developing countries." Tech. rep.

63. Rubin, D. B. (1976): “Inference and missing data,” Biometrika, 63, 581-592.

64. Salisbury, F. B. and B. Bugbee (1988): "Plant productivity in controlled environments." American Society for Horticultural Science, 23, 293-299. 
65. Stanley, T., H. Doucouliagos, M. Giles, J. H. Heckemeyer, R. J. Johnston, P. Laroche, J. P. Nelson, M. Paldam, J. Poot, G. Pugh, R. S. Rosenberger, and K. Rost (2013): "Meta-analysis of economics research reporting guidelines," Journal of Economic Surveys, 27, 390-394.

66. Sutton, A. J., S. Duval, R. Tweedie, K. R. Abrams, and D. R. Jones (2000):

67. "Empirical assessment of effect of publication bias on meta analyses," British Medical Journal, 320, 1574-1577.

68. Swanson, B. (2006a): Improving agricultural extension, Daya Books.

69. Swanson, B. E. (2006b): "Seminal Article Series: The Changing Role of Agricultural Extension in a Global Economy," Urbana, 13, 5-17.

70. Thiam, A., B. E. Bravo-Ureta, and T. E. Rivas (2001): "Technical efficiency in developing country agriculture: A metaanalysis," Agricultural Economics, 25, 235-243.

71. Umali-Deininger, D. (1997): “Public and private agricultural extension: Partners or rivals?” The World Bank Research Observer, 12, 203-224.

72. Villano, R., B. Bravo-Ureta, D. Sol'Is, and E. Fleming (2015): "Modern rice technologies and productivity in the Philippines: Disentangling technology from managerial gaps," Journal of Agricultural Economics, 66, 129-154.

73. Wollni, M. and B. Brummer" (2012): "Productive efficiency of specialty and conventional coffee farmers in Costa Rica: Accounting for technological heterogeneity and selfselection," Food Policy, 37, 67-76.

74. World Bank (2016): “New country classification," available at: http://data. worldbank.org/news/new-countryclassifications-2015 assessed on 20 April 2018.

\section{Tables}

Table 1: Weighted least square meta-regression analysis with complete case and multiple imputation 


\begin{tabular}{|c|c|c|c|c|c|c|c|c|}
\hline & \multicolumn{4}{|c|}{ Inverse Standard Errors } & \multicolumn{4}{|c|}{ Inverse Range } \\
\hline & \multicolumn{2}{|c|}{ Complete Case (la) } & \multicolumn{2}{|c|}{ Imputation (Ib) } & \multicolumn{2}{|c|}{ Complete Case (IIc) } & \multicolumn{2}{|c|}{ Imputation (IId) } \\
\hline & Estimate & Std. Error & Estimate & Std. Error & Estimate & Std. Error & Estimate & Std. Error \\
\hline Constant & 0.390 & $0.121 * * *$ & 0.469 & $0.128 * * *$ & 0.285 & $0.139 * *$ & 0.469 & $0.141 * * *$ \\
\hline $\begin{array}{l}\text { Extension } \\
\text { services }\left(\beta_{1}\right)\end{array}$ & 0.065 & $0.027^{* *}$ & 0.048 & $0.029 * *$ & 0.076 & $0.029 * * *$ & 0.048 & $0.024^{* *}$ \\
\hline $\begin{array}{l}\text { Vegetables } \\
\text { and melons } \\
\text { (Crops2) }\end{array}$ & 0.274 & $0.135^{* *}$ & 0.285 & $0.134^{* *}$ & 0.266 & $0.13^{* *}$ & 0.285 & $0.128^{* *}$ \\
\hline $\begin{array}{l}\text { Oil seed } \\
\text { (Crops4) }\end{array}$ & -0.020 & 0.025 & -0.025 & 0.028 & -0.015 & 0.022 & -0.025 & 0.025 \\
\hline $\begin{array}{l}\text { Root/Tuber } \\
\text { (Crops5) }\end{array}$ & -0.024 & 0.041 & -0.023 & 0.046 & -0.024 & 0.034 & -0.023 & 0.041 \\
\hline $\begin{array}{l}\text { Beverage and } \\
\text { species } \\
\text { (Crops6) }\end{array}$ & -0.047 & 0.105 & -0.012 & 0.094 & -0.041 & 0.105 & -0.012 & 0.088 \\
\hline $\begin{array}{l}\text { Non-food } \\
\text { (Crops9) }\end{array}$ & -0.031 & 0.041 & -0.033 & 0.046 & -0.029 & 0.034 & -0.033 & 0.041 \\
\hline $\begin{array}{l}\text { Miscellaneous } \\
\text { (Crops10) }\end{array}$ & -0.018 & 0.05 & -0.027 & 0.054 & -0.005 & 0.045 & -0.027 & 0.051 \\
\hline $\begin{array}{l}\text { Low income } \\
\text { economy (LIE) }\end{array}$ & -0.141 & $0.069 * *$ & -0.128 & $0.067^{* *}$ & -0.136 & $0.067^{* *}$ & -0.128 & $0.062^{* *}$ \\
\hline $\begin{array}{l}\text { Middle } \\
\text { income } \\
\text { economy } \\
\text { (MIE) }\end{array}$ & -0.028 & 0.036 & -0.026 & 0.03 & -0.019 & 0.042 & -0.026 & 0.033 \\
\hline $\begin{array}{l}\text { Upper middle } \\
\text { income } \\
\text { economy } \\
\text { (UMIE) }\end{array}$ & -0.079 & $0.02^{* * *}$ & -0.080 & $0.018^{* * *}$ & -0.069 & $0.015^{* * *}$ & -0.080 & $0.013^{* * *}$ \\
\hline $\begin{array}{l}\text { High income } \\
\text { economy (HI) }\end{array}$ & 0.399 & $0.069 * * *$ & 0.401 & $0.071^{* * *}$ & 0.408 & $0.065^{* * *}$ & 0.401 & $0.067^{* * *}$ \\
\hline $\begin{array}{l}\text { Data } \\
\text { envelopment } \\
\text { analysis } \\
\text { (DEA) }\end{array}$ & 0.153 & $0.082 *$ & 0.116 & $0.059 * *$ & 0.151 & $0.08^{*}$ & 0.116 & $0.053^{* *}$ \\
\hline $\begin{array}{l}\text { Cross- } \\
\text { sectional data } \\
\text { (TYPE) }\end{array}$ & -0.121 & 0.074 & -0.100 & $0.058^{*}$ & -0.107 & 0.077 & -0.100 & $0.057^{*}$ \\
\hline $\begin{array}{l}\text { Number of } \\
\text { observations } \\
\text { (OBS) }\end{array}$ & 0.015 & 0.012 & 0.004 & 0.015 & 0.030 & $0.015^{*}$ & 0.004 & 0.017 \\
\hline $\begin{array}{l}\text { Cobb-Douglas } \\
\text { function } \\
\text { (CDD) }\end{array}$ & 0.011 & 0.14 & -0.031 & 0.127 & 0.033 & 0.137 & -0.031 & 0.122 \\
\hline Trans-log & 0.179 & $0.081^{* *}$ & 0.140 & $0.055^{* * *}$ & 0.182 & $0.081^{* *}$ & 0.140 & $0.05^{* * *}$ \\
\hline
\end{tabular}




\begin{tabular}{|lllll|}
\hline function (TF) & & & & \\
FE Study/Year & Yes & Yes & Yes & Yes \\
\hline Observations & 314 & 335 & 314 & 335 \\
\hline Weighted $R^{2}$ & 0.808 & 0.790 & 0.815 & 0.804 \\
\hline AlC & -417.181 & -276.93 & -429.578 & -295.76 \\
\hline BIC & 347.696 & 578.48 & 335.298 & 559.65 \\
\hline
\end{tabular}

Note. ${ }^{*} p<0.1{ }^{* *} p<0.05 ; * * * p<0.01$

Cluster robust standard errors at the study/year level are given in parentheses

Reference category for country classification = Lower-Middle Income Economy (LMIE)

Reference category for crop classification = Cereals (Crop 1$)$

Reference category for specification of production function = Other Functional Form (Other)

Table 2: Effect of agricultural extension on technical efficiency using inverse propensity score weighting technique and complete case analysis 


\begin{tabular}{|c|c|c|c|c|c|c|}
\hline & \multicolumn{2}{|l|}{ Model (1) } & \multicolumn{2}{|l|}{ Model (2) } & \multicolumn{2}{|l|}{ Model (3) } \\
\hline & Estimate & Std. Error & Estimate & Std. Error & Estimate & Std. Error \\
\hline Constant & 0.434 & $0.133^{* * *}$ & 0.467 & $0.123^{* * *}$ & 0.542 & $0.128 * * *$ \\
\hline Extension services $\left(\beta_{1}\right)$ & 0.064 & $0.030 * *$ & 0.072 & $0.028 * *$ & 0.054 & $0.031 *$ \\
\hline Vegetables and Melons (Crops2) & 0.286 & $0.142 * *$ & 0.255 & $0.144^{*}$ & 0.269 & $0.140 *$ \\
\hline Oil seed (Crops4) & -0.026 & 0.026 & -0.035 & 0.028 & -0.048 & 0.030 \\
\hline Tuber/root (Crops5) & -0.026 & 0.043 & -0.048 & 0.039 & -0.051 & 0.044 \\
\hline Beverages and species (Crops6) & -0.053 & 0.110 & -0.104 & 0.105 & -0.095 & 0.107 \\
\hline Non-food (Crops9) & -0.035 & 0.044 & -0.056 & 0.040 & -0.061 & 0.045 \\
\hline Miscellaneous (Crops10) & -0.039 & 0.055 & -0.043 & 0.053 & -0.055 & 0.057 \\
\hline Low income economy (LIE) & -0.139 & $0.075^{*}$ & -0.163 & $0.071 * *$ & -0.163 & $0.073 * *$ \\
\hline Middle income economy (MIE) & -0.041 & 0.041 & -0.036 & 0.038 & -0.039 & 0.035 \\
\hline Upper middle income economy (UMIE) & -0.089 & $0.025^{* * *}$ & -0.083 & $0.021 * * *$ & -0.086 & $0.022 * * *$ \\
\hline High income economy (HIE) & 0.397 & $0.075^{* * *}$ & 0.386 & $0.07^{* * *}$ & 0.384 & $0.073 * * *$ \\
\hline Data envelopment analysis (DEA) & 0.200 & $0.083^{* *}$ & 0.194 & $0.083^{* *}$ & 0.181 & $0.084^{* *}$ \\
\hline Cross-sectional data (TYPE) & -0.144 & $0.079 *$ & -0.166 & $0.078 * *$ & -0.162 & $0.077 * *$ \\
\hline Number of observations (OBS) & 0.007 & 0.012 & 0.008 & 0.012 & -0.002 & 0.014 \\
\hline Cobb-Douglas function (CDD) & 0.020 & 0.141 & 0.024 & 0.144 & -0.004 & 0.139 \\
\hline Trans-log function (TF) & 0.202 & $0.076^{* * *}$ & 0.197 & $0.076^{* *}$ & 0.189 & $0.078 * *$ \\
\hline FE Study/Year & Yes & & Yes & & Yes & \\
\hline Observations & 314 & & 314 & & 314 & \\
\hline Weighted $R^{2}$ & 0.803 & & 0.797 & & 0.788 & \\
\hline AIC & -352.906 & & -359.682 & & -357.530 & \\
\hline $\mathrm{BIC}$ & 411.976 & & 405.194 & & 407.346 & \\
\hline
\end{tabular}

Note. ${ }^{*} p<0.1, * * p<0.05 ; * * * p<0.01$

Cluster robust standard errors at the study/year level are given in parentheses

Reference category for country classification = Lower-Middle Income Economy (LMIE)

Reference category for crop classification = Cereals $($ Crop 1$)$

Reference category for specification of production function = Other Functional Form (Other) 


\section{Figures}

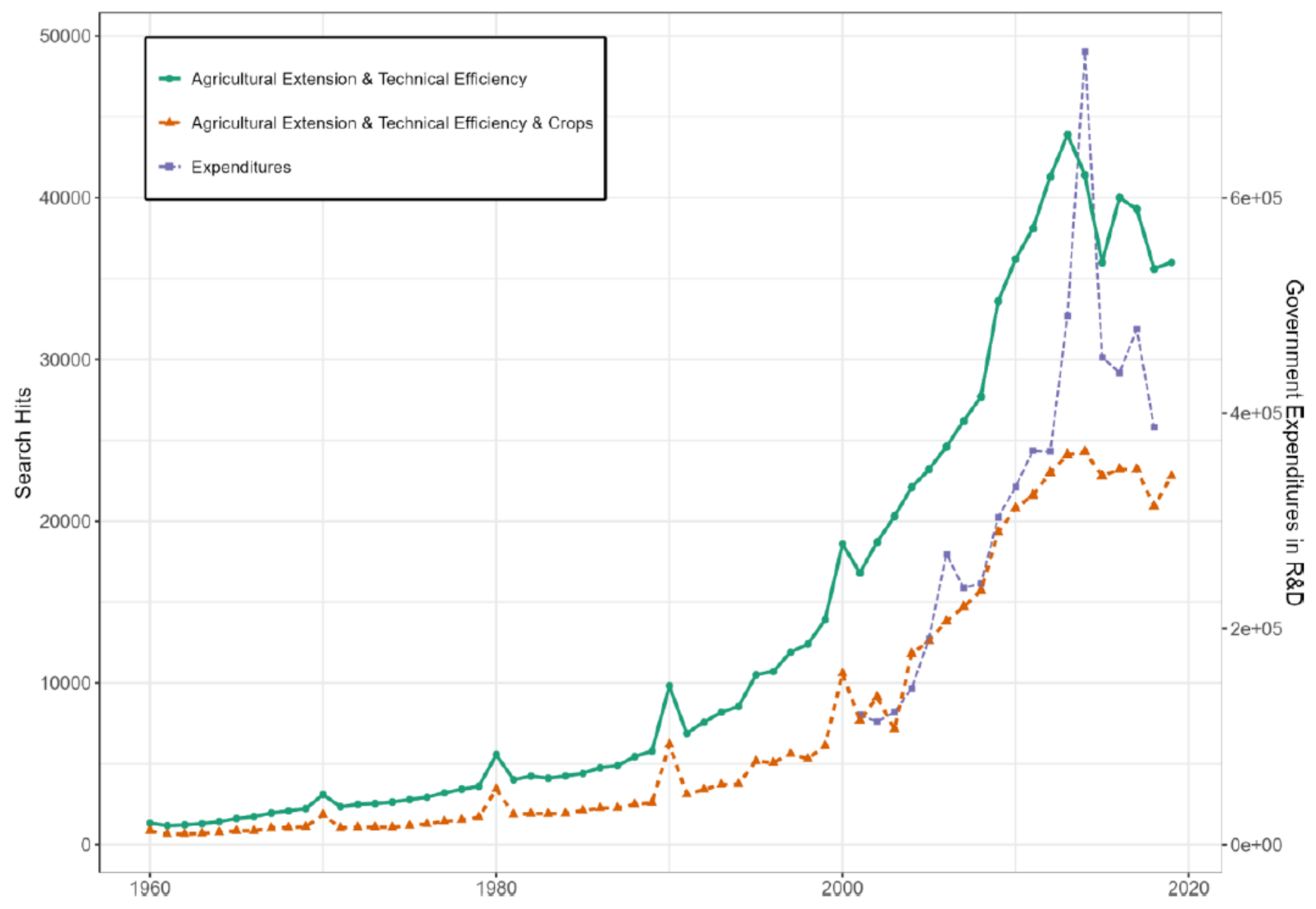

Figure 1

Saliency of agricultural extension in government spending and scientific articles using google search hits Note. Government expenditures in R\&D is provided by FAO statistics 


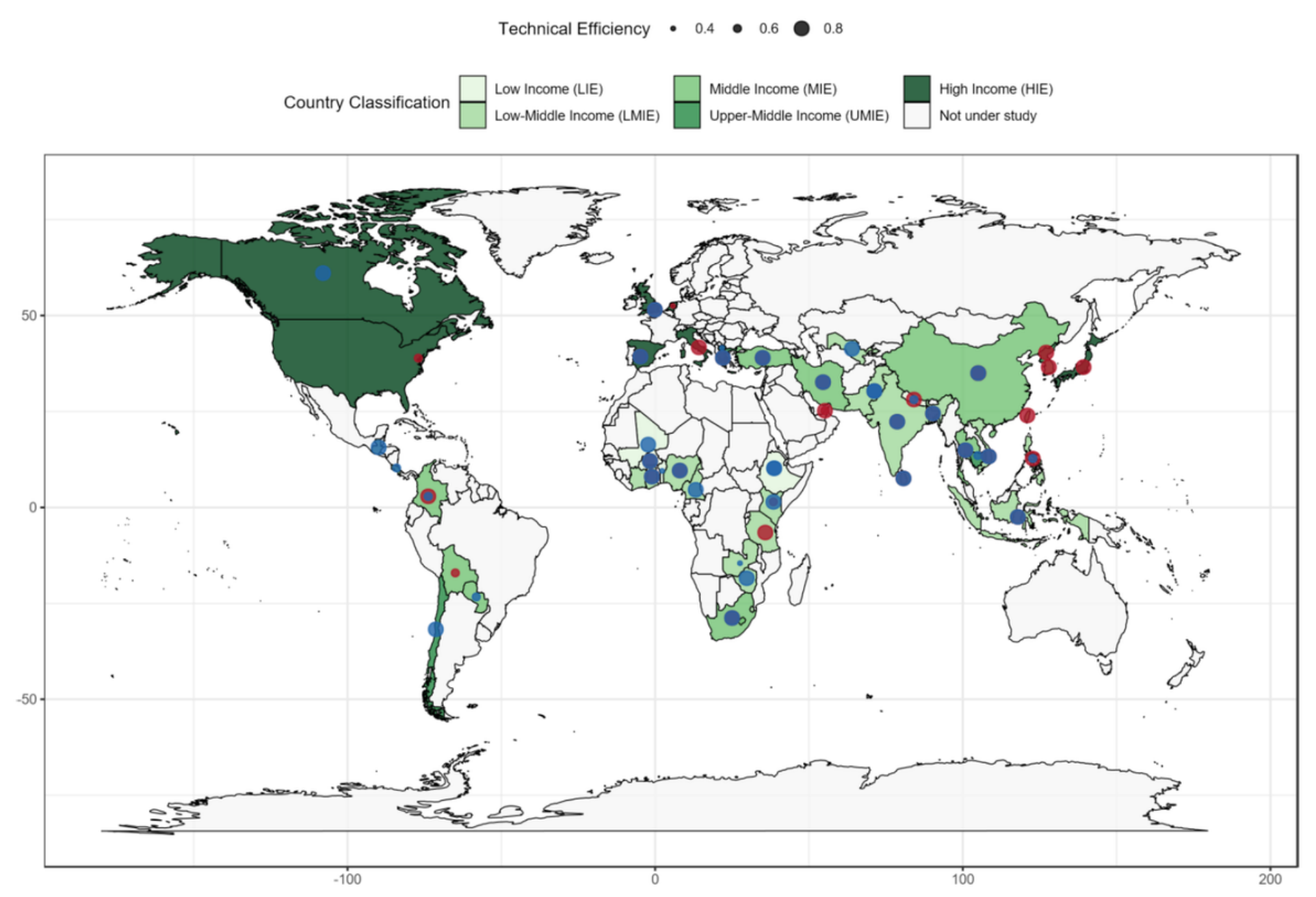

\section{Figure 2}

Geographical distribution of crop studies in meta-analysis Note. Redish and blueish dots capture farm studies excluding and including agricultural extension programs, respectively. Size of the dots denotes the average technical efficiency. Open the shiny web app https://eussue.shinyapps.io/meta_analysis/ in mozilla browser for interactive mode. Customized crop icons are placed on the centroid of the country under study, as large majority does not report explicitly study area. 


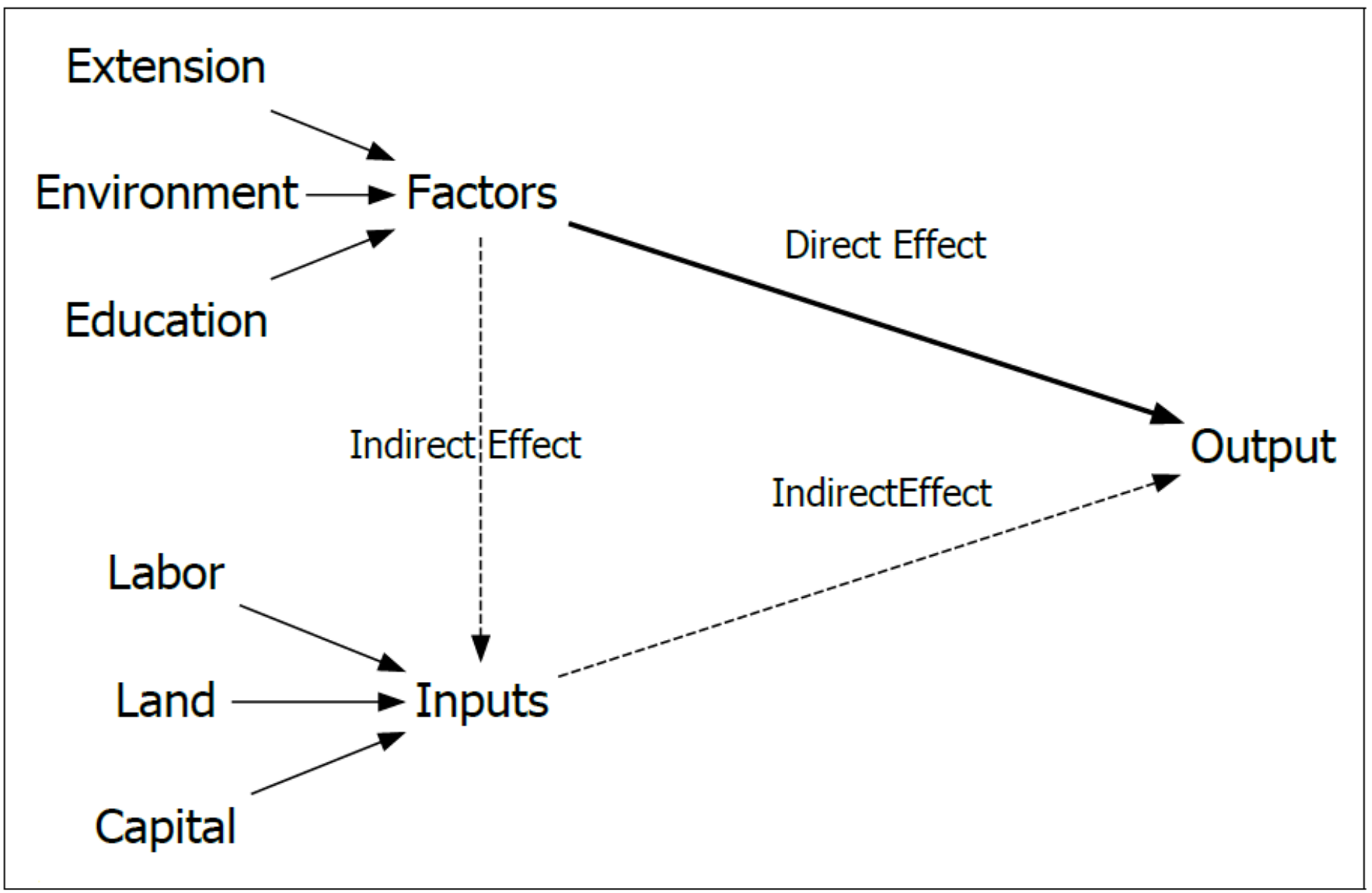

Figure 3

Causal paths of agricultural extension and technical efficiency

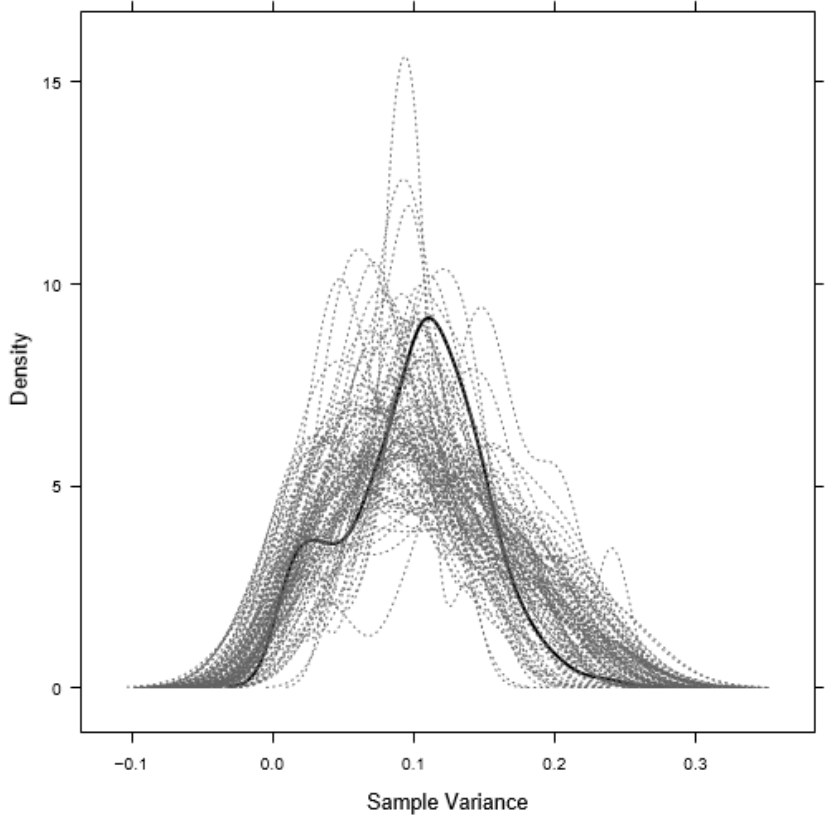

(a) Variance



(b) Range

Figure 4 
Distribution of original and imputed values using predictive mean matching Note. Dotted and dashed line denote the original and imputed distribution, respectively
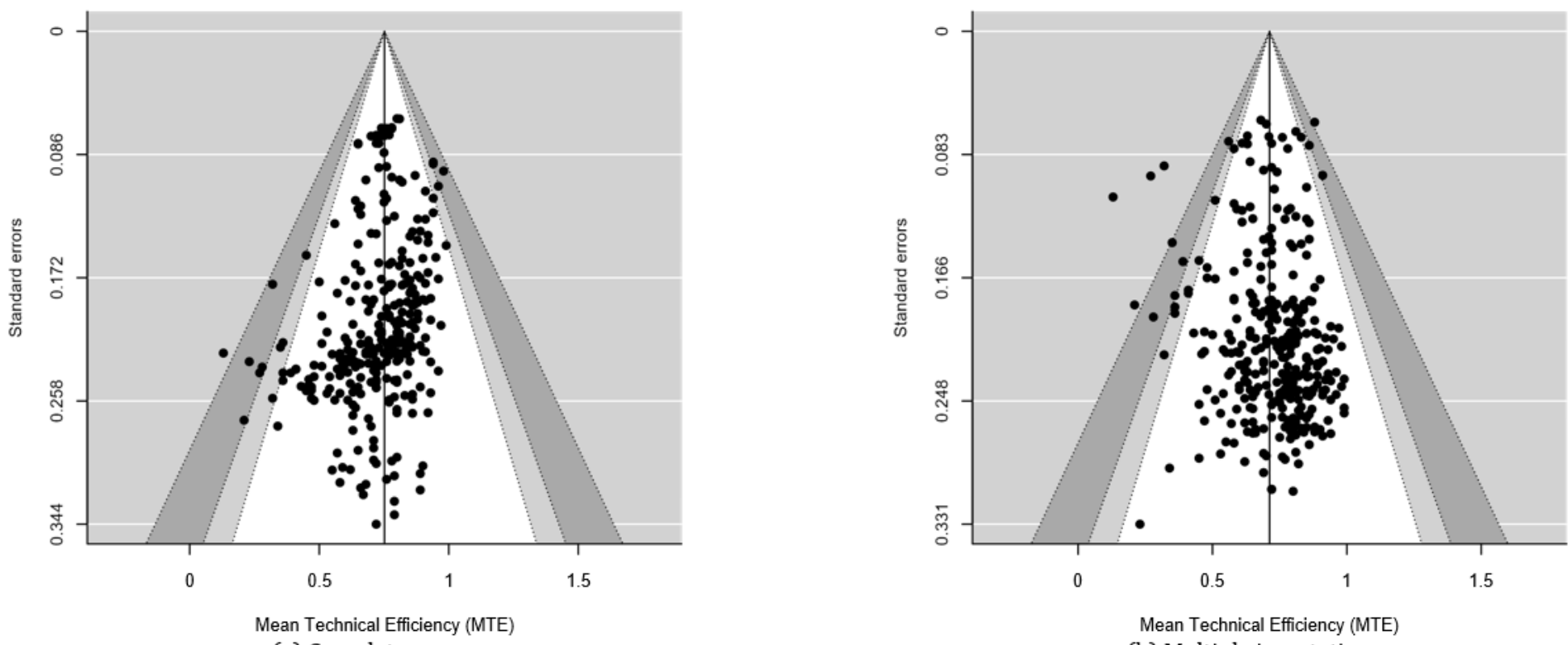

(a) Complete case

(b) Multiple imputation

Figure 5

Funnel Plot with confidence intervals Note. Dots represents the observed effect sizes. The solid vertical line denotes the overall mean effect of the technical efficiency applying fixed effects weighted regression. From inside to outside, the dashed lines limit the $90 \%, 95 \%$, and $99 \%$ confidence intervals.
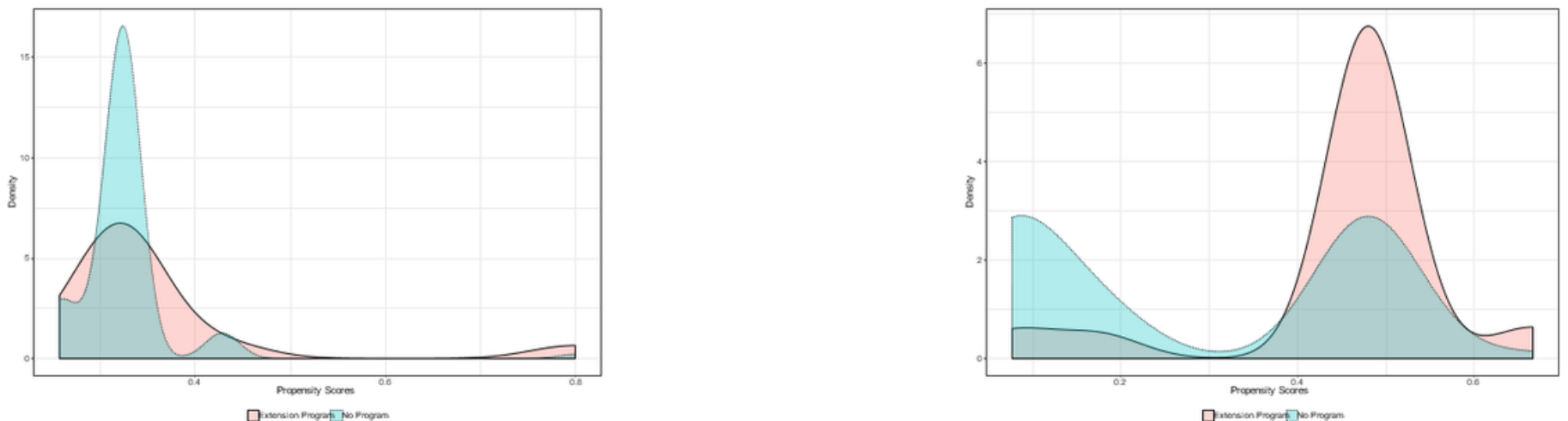

(a) Model (1)

(b) Model (2)

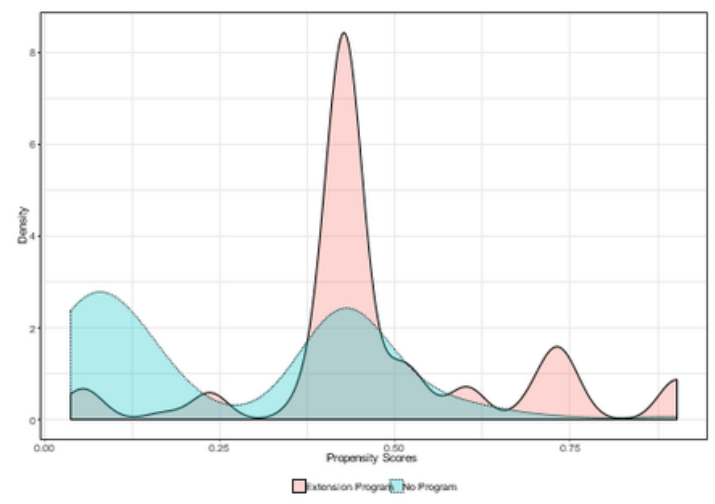

(c) Model (3) 
Distribution of propensity scores across models

\section{Supplementary Files}

This is a list of supplementary files associated with this preprint. Click to download.

- SupplementaryMaterials.docx 